\title{
Anti-realism or pro-something else? Response to Deichsel
}

\author{
TONY LAWSON \\ University of Cambridge
}

Keywords: realism, anti-realism, ontology, mainstream economics JEL Classification: B40, B41, B49

In those parts of his paper that have the clearest bearing upon my contributions, Simon Deichsel 1) elaborates various conceptions of realism; 2) declares himself an anti-realist of a specific sort; 3) seeks to identify and criticise pragmatic aspects of my justification for adopting a realist orientation; and 4) argues that his anti-realist perspective is preferable to realism.

An immediate problem with Deichsel's project, if intended as a critique of my own realist orientation, is that the sort of realism against which his anti-realism is oppositionally defined is not the version of realism I maintain. In fact the only one of Deichsel's formulations that I unambiguously accept as a version of realism is (in his terms) ontological realism. Realism as I understand the term is about existence. It is ontological in nature. At its most basic, it posits the existence of an 'external' reality. ${ }^{1}$

So understood, realism is not a theory of knowledge, or of language, or even of truth. Indeed so formulated it says nothing about knowledge or truth. ${ }^{2}$ In particular it does not commit anyone to the correspondence theory of truth, or indeed to any other theory or conception of truth. In fact it is not a semantic theory at all.

\footnotetext{
${ }^{1}$ Use of the term "external" here should not be taken to exclude the possibility of a social reality whose existence is at least in part dependent on us.

${ }^{2}$ Of course, one could formulate a (truth) realism positing the existence of the truth of propositions or some such. But I have never sought to elaborate such a conception. To posit the existence of any phenomenon $X$ is an ontological theory that can with reason be termed realism about $\mathrm{X}$.
} 
Of course I do accept notions (and the possibility) of truth, though I find the idea of a correspondence theory to be potentially misleading (there could be no literal correspondence between theory and any nonlinguistic aspects of reality-see, e.g., Lawson 1997, chapter 17, for a discussion). At the simplest level (for truth is, or can be, a multifaceted and complex notion ${ }^{3}$ ), I accept an objective 'expressive referential' conception of truth whereby theories are true or not just in virtue of the way the world is; that is, our expressions are true or not just in virtue of the nature of the referents of our expressions. Clearly this conception, if it is not to be empty, presupposes that theories can refer. Perhaps we can think of the correspondence theory metaphorically as an expressive-referential account of truth. But whilst such a metaphorical version of the correspondence theory of truth does (like any other version) presuppose (ontological) realism, realism can be accepted without any acceptance even of the metaphorical version. Realism of the sort I maintain, to repeat, is not a theory of truth and it carries no necessary implications regarding theories of truth.

I might emphasise that I do not think it possible to prove the existence of an external reality. However, I think it is possible to show that my opponents and everyone else are as committed to an external world as I am, and are even committed to many of the existents to which I commit. In particular Deichsel reveals himself to be as committed as I am to the existence of discussion and debate in modern economics. He even tells us that "it is not obvious that [my] social ontology gives us a realistic representation of the social world" (Deichsel 2011, 35); and describes my "claim that mainstream economics is not successful with accommodating the data" as "at best only a half-truth" (p. 36). It does not take too much to see that in so arguing he presupposes the existence of an external reality (whatever we think of his claims), and even of a social reality that does not reduce to our conceptions.

Of course, in so arguing I am presupposing that there is intelligibility in the world, including in our linguistic communications. I cannot imagine that, or how, anyone would reasonably deny this, but it is an

\footnotetext{
${ }^{3}$ The word "true" has the same etymological root as the words "trustworthy" and "trust" and can mean reliable, as in a true friend. We might also talk of true believers, or true north. The essence of something is sometimes expressed by the (ontological) alethic truth.
} 
assumption or principle worth making explicit. ${ }^{4}$ But clearly to suppose that reality is intelligible first necessitates a commitment to realism as I understand the thesis.

So if Deichsel does not seem opposed to realism of the sort I maintain, to what kind of anti-realism does he subscribe? Deichsel's conception of anti-realism runs as follows:

I take anti-realism as the thesis that we should suspend judgement on the truth and truth-worthiness of our theories or avoid talking about the truth of theories altogether in order to minimize the confusions that surround this concept (Deichsel 2011, 24).

Clearly, then, this is explicitly not anti- the sort of realism I defend at all. If ontological realism as Deichsel conceives it, and which I maintain, were the focus of Deichsel's anti-realism, then the latter would be formulated as something like the rejection of any theory- or representation-independent reality. ${ }^{5}$ However the latter, as we have seen, is seemingly not Deichsel's position. His anti-realism is not an ontological doctrine at all. In fact, in a footnote to his statement on antirealism, Deichsel adds that he does "not claim that no theory can be possibly true" only that "we should avoid talking about the truth of theories" (p. 24, n. 2).

\footnotetext{
${ }^{4}$ Indeed I have. Thus in Lawson 2003, for example, I write:
}

The alternative point of departure adopted is to suppose of scientific practices not that they are inevitably rational, but that they (and indeed all human practices) are intelligible. That is, it is accepted that all actual practices, whether or not scientific, and whether or not successful on their own terms, have explanations. There are conditions which render practices actually carried out (and their results) possible. Let me refer to this supposition as the intelligibility principle (to heighten the contrast with Popper's rationality principle, that individuals always act appropriately to their situations, see Popper 1967: 359). Thus, accepting the intelligibility principle, one strand of my strategy has just been to seek to explain (aspects of) certain human actions, to identify their conditions of possibility. Or, more precisely, my strategy has been to explain various generalised features of experience, including human actions, and so to uncover generalised insights regarding the structure or nature of reality. This of course, is precisely an exercise in ontology (Lawson 2003, 33).

${ }^{5}$ To the extent that we are implicitly, as I am, taking the notion of the 'external' to include the possibility of a social reality that may be in part dependent on but (again in part at least) irreducible to human representations, or at least of the representations of anyone including scientists currently examining it, then a relevant form of an antirealism might choose to emphasise that the rejection of any representationindependent reality incorporates the rejection of any representation-independent (aspects of) social reality. 
I must admit that, given this qualification along with the disjunctive (either-or) nature of Deichsel's formulation of anti-realism, I myself would be reluctant to interpret this as much of an anti-realist position of any sort. Rather his position simply seems to be that talking of truth can confuse, so if we cannot suspend making truth judgements of our theories we should, for clarity, at least avoid referring to them as true or false.

Certainly that is feasible, up to a point. For sure, on my conception a theory is true, when it is, not because of its degree of empirical support, but because of the way the world is. So the fact that a theory may be well supported by the evidence does not necessitate that it is true, certainly not in all respects, and so any caution in referring to a theory as true or even approximately true is understandable, especially in the context of scientific-explanatory work. Indeed in my own ontologicalexplanatory and scientific-explanatory research I do mainly talk of theories that are the most explanatorily powerful or better grounded. I do not think I ever claim explicitly that a theory that I support is true. So long as we include within our list of criteria of theory evaluation some that are ontological/evidential-and Deichsel apparently supports the use of criteria like "empirical adequacy", viewed as "ontologically more parsimonious" than truth (p. 30)-there does not seem a difference here. This doesn't mean that I do not believe that many of the scientific and ontological claims I make, are true, or contain significant truth (truth comes in degrees); but I tend not to mention this, and rather indicate merely some of the grounding for the claims or hypotheses in question.

Of course, it is impossible to indicate the evidential and other support for claims that are continually born out in everyday practice. Indeed, many lay people (and I suspect most of us) regularly use the terms true and false to denote representations that are continually found successfully to express their intended referents. ${ }^{6}$ Given the highly qualified nature of Deichsel's pragmatic orientation, I assume he is not really bothered by statements like 'it is true that snow is white', or 'it is true that the grass in front of me is green', or 'yes, it is true that my name is Simon'. Technically perhaps such statements should be read as 'I believe it to be true that snow is white', and so on. But I am not sure

\footnotetext{
${ }^{6}$ And to the extent that most if not all claims or statements are representations, then if they are to be understood as statements they also need to be understood as representations (with associated truth values).
} 
that such everyday comments really are capable of causing the sort of confusion that appears to be Deichsel's primary concern, at least not in everyday contexts.

In science, though, especially where discovery and explanation are involved, I agree there is a clear need for caution. I have used terms like realistic (which incidentally I think only a few, and mostly economists, have ever conflated with the term realism) to stand in as expressing theories or claims we take to be pervasively and perhaps without apparent exception grounded in every day experience and so forth.

The noteworthy feature of the output of modern mainstream economic modelling, in this respect, is that many features of the (believed-to-be) truths of every day social life-representations that are continually born out in practice, and which I therefore feel can reasonably be described as realistic-are regularly implicitly denied or anyway replaced by contradictory representations. So I do use terms like unrealistic (accepted-as-false or superficial, and the like) when describing the theories and models of the mainstream. Thus I have employed the term unrealistic to describe claims or "assumptions" like perfect foresight, omniscience, rational expectations, infinitely and perfectly calculating human individuals, two-commodity worlds, isolated economies, along with most of the (other) driving assumptions of modern economic modellers. Not only are such unrealistic claims everywhere apparent, it is even the case that they are mostly advanced for no better reason than their ability to facilitate model tractability.

Notice parenthetically that the terminology of 'unrealistic', 'superficial' and even 'false' is often that adopted by modellers themselves. ${ }^{7}$ Deichsel may prefer different terms to those I use-though as we have already noted, when discussing my social ontology he is content to question whether it gives a "realistic representation"-but differences here, if they exist, seemingly turn on semantics and strategy at most. And none of this pertains to the positive social ontological and social scientific results I actually maintain. So whatever else Deichsel might be opposing in my contributions his anti-realism is not only not opposed to my basic formulation of realism, it is not even

\footnotetext{
${ }^{7}$ Robert Lucas writes for example: "To observe that economics is based on a superficial view of individual and social behavior does not seem to me to be much of an insight. I think it is exactly this superficiality that gives economics much of the power that it has: its ability to predict human behavior without knowing very much about the make up and lives of the people whose behavior we are trying to understand" (Lucas 1986, 425). And David Hendry is one of numerous econometricians who continually assert that "all models are false" (see, e.g., Hendry 1997).
} 
inconsistent with the manner of my rendering of the results of my investigations.

\section{AN ORIENTATION TO ONTOLOGICAL ELABORATION}

It will be apparent from the foregoing that (I believe) we are basically all (ontological) realists. If that is so, the question can fairly be put as to why I have bothered ever to identify or distinguish my position as realist at all. What has been my purpose in doing so, ${ }^{8}$ especially since-as Dan Hausman (1998) notes-there are few if any economists that profess to be opposed to (ontological) realism?

The answer is that, for strategic reasons, I have used the adjective realist to signal a particular orientation, namely one involving explicit, systematic and sustained attention to ontological elaboration. That is, I have argued for an ontological turn in social theory and at certain points, with realism itself being an ontological position, I identified such a stance as realist. But in so doing I was careful to stress that I was seeking to distinguish my position not from anti-realism but from approaches in which the ontological commitments were left implicit and unexamined. That is, I was seeking to distinguish my position from others that, although realist in the noted sense, were, I believed, not being realist enough. ${ }^{9}$

\footnotetext{
${ }^{8}$ Notice that this is different to merely acknowledging a commitment to ontological realism. The latter too is essential not least because there are those who, however incoherently, seek to reject ontological realism. And the contributions of these antirealists matter. It is this rejection of ontological realism that has been necessary to, and often even drives, the rejection of the possibility of objectivity or progress, including rational comparative assessment in knowledge, truth, human emancipation, and so forth. However these anti-realisms are positions rarely if at all to be found in economics. If they were, and were a commonplace, it would already be clear why I have chosen to identify or distinguish my project as realist.

${ }_{9}$ Thus in response to Dan Hausman's question as to why my project might be distinguished as realist I wrote:
}

And it brings me to Hausman's second worry about explicitly labelling a project realist: that so doing 'inevitably suggests that the competing programs [...] fail to be realist enough'. There is a sense in which this is exactly what I am suggesting.

In identifying my project as realist I am first and foremost wanting to indicate a conscious and sustained orientation towards examining, and formulating explicit positions concerning, the nature and structure of social reality, as well as investigating the nature and grounds of ontological (and other) presuppositions of prominent or otherwise significant or interesting contributions. And I am wanting to suggest that it is precisely this sort of explicit concern with questions of ontology that is (or has been) lacking in modern economics. This is an absence, indeed, that I believe contributes significantly to the discipline's current malaise. In this sense of the term, in my view, most of the projects contributing to the development of modern economics are not nearly realist enough (Lawson 2003, 72). 
Just as identifying some of us as cooks, or singers, or students indicates a sustained commitment to various practices associated with these positions without implying that the rest of us do not cook or sing or study (or even less that we are somehow anti-cooking, anti-singing, or anti-studying), so in identifying a sustained concern with ontology as realist I meant to signal a contrast only with those whose ontological commitments were relatively poorly elaborated; I intended no suggestion that ontological presuppositions were denied, or that some similar kind of anti-realist position was implied.

I might add that since the term ontology has, in recent years, become more commonplace in modern (heterodox) economics and indeed in social theory quite widely, I have been content to describe my basic project simply as one in social ontology.

The practice of using the adjective 'realist' to indicate an ontological emphasis is important here because it is primarily this emphasis that Deichsel seeks to show lacks pragmatic justification. I will now consider his arguments. But first let me note that even this use of the term realist clearly designates a position to which Deichsel's specific formulation of anti-realism does not of necessity stand in opposition. Even so, Deichsel's criticisms of what he identifies as my pragmatic reasons for accepting the stance that I do may be sound nevertheless. So let me now examine how they proceed. On this Deichsel writes:

Lawson states that in some sense nearly everybody is a realist because even methodological anti-realists often accept ontological realism. For this reason he defines his blend of realism by its "sustained concern with ontology" (Lawson 2001, 168). By this focus on ontology, Lawson hopes to learn something about the nature of social phenomena, which he thinks will enable him to give better methodological advice to economists than anti-realists can. This is a pragmatic defence of realism as it concentrates on the positive consequences of adopting critical realism (Deichsel 2011, 28).

Notice, to repeat, that in my own terms such a pragmatic justification would suggest only that sustained ontological analysis is capable of providing insight that may be unavailable to those who neglect ontology. If the above passage does interpret those who do so neglect ontology as anti-realist this is Deichsel's terminology not mine.

Reconstructing Deichsel's argumentation a little, his critique of my contribution seemingly involves an opposition to 1) the whole endeavour in principle; 2) the way the ontological results are achieved; 
and 3) the sorts of results achieved (including methodological implications).

Let me consider these three aspects to his critique in reverse order, starting with results achieved. In order to assess the effectiveness of Deichsel's criticisms here it is necessary that I first briefly sketch the features of my ontological results that are relevant to this point. They are the following.

First, and putting things momentarily in my own terms, I indicate that the familiar mainstream insistence that deductivist methods of modelling be everywhere employed presupposes (if these methods are generally to provide insight) that social reality is everywhere closed (that is, it consists of systems in which event regularities occur). And the restriction to addressing closed systems tends understandably to result in substantive economic formulations couched in terms of isolated atoms, an ontology that guarantees that closure is achieved.

Second, I argue that social reality is however not everywhere closed. So the mainstream insistence upon deductivism is a problem. However, I do not conclude that this assessment undermines explanatory analysis. For I additionally argue that social reality is structured in complex ways. Specifically, there are identifiable causal structures that underpin social events and co-produce them, structures that, I argue, are (amongst other things) emergent, agent-dependent, dynamic, and highly internally related (constituted in relation to each other).

So amongst the methodological implications of my ontological analysis is that the explanatory endeavour will often require that we seek to indentify the underlying causal structures responsible for actual events, and that reliance on deductivism as a generalised approach to social analysis is a mistake.

A further implication is that, given the open, emergent and internally-related nature of social phenomena, methods of theoretical idealisation, which rest on the initial formulation of closures as heuristic devices (involving conceptions of isolated causes or some such that might hopefully eventually be mechanistically/additively combined with others or otherwise elaborated) are unlikely to facilitate much insight into social reality; they are inappropriate methods for the ontological context (see Lawson 1997; 2009c).

So how does Deichsel proceed in criticising my assessment? The nub of his argument at this point seems to take the form of three basic "reasons" for rejecting my position. Using the terminology of "real 
forces" to express the causal structures which (I argue) underpin many social phenomena, Deichsel writes:

There are at least three reasons why I disagree with [Lawson's] position: first, we cannot know what the "real forces" are; second, [Lawson's] proposal can be turned against any form of idealisation; and third, it is doubtful whether mainstream economics is well characterised by Lawson's interpretation of the term "deductivism" at all (Deichsel 2011, 34).

I have written so much on all this that I hope it is sufficient here to make just a few summary comments on each "reason" briefly in turn.

If the worry about not being able to know the real forces means not being able in principle to say anything about them, and in particular that it is not possible to rationally evaluate competing hypotheses about underlying causal structures (just as we evaluate all other hypotheses whether in social or 'natural' science, and this surely is all that matters here), then the worry is unfounded. Specific substantive theories or hypotheses about causal structures (or 'real forces') and the like, are defended, as in any other science, according to their relative explanatory power in relation to relevant empirical and other phenomena upon which the theories in question bear implication (see, e.g., Lawson 2003, chapter 4; 2009a; 2009b; 2009e).

Second, it is not the case (and certainly not a claim I make) that my "proposal can be turned against any form of idealisation", and in particular not against those idealisations formulated within natural science that can produce (typically experimental) conditions that approximate (but only approximate) closures. But my proposal certainly can be turned against most of the idealisations of modern economics. However, I cannot see that this itself is a self-evident defect of my results or position; not unless avoidance of criticism of the status quo, the hugely dominant current mainstream project, is the overriding objective. Deichsel adds, as if developing an argument:

There are many theories that would have to be abolished right away if Lawson's [position] was uniformly accepted. Just think of formal decision theory, game theory, any theory employing folk psychological reasoning, any form of hypothetical contractarianism and even political liberalism, because they are all admittedly based on unrealistic assumptions (Deichsel 2011, 35). 
The rhetoric of "abolished" is not mine. But I agree that these topics and approaches would likely attract significantly less attention if my assessment were to be widely recognised and accepted. But, to repeat, it is not much of a case against my position merely to indicate the radical or unpalatable nature of its consequences for current mainstream practice.

Parenthetically, in various places (for example in Lawson 1997; and 2009c), I do address the issue of idealisations in economics at length. In particular I identify the sorts of conditions in which methods of theoretical idealisation can be legitimately applied. I show that even where (or if) such conditions do (or were to) hold the methods in question remain both unnecessary and ultimately inhibiting. But I also argue, as an empirical assessment, that in the social realm, such conditions rarely emerge at all.

Third, Deichsel's rejection of my interpretation of the nature of modern mainstream economics as deductivist seems to rest on an assessment that mainstream economics can allow, and indeed sometimes posits, the existence of underlying structures.

But I do not deny this (see, e.g., Lawson 2003; or 2009d). That is why I characterise the mainstream project as deductivist rather than, say, positivist or empiricist (for its empirical wing). My argument rather is the following. A characteristic feature of deductivist explanation is its essential reliance upon closures (supporting real or constructed event regularities) of the sort that are a necessary condition for the sort of mathematical modelling endeavour in which mainstream economists insist on engaging. Now the relevant problem here (one of many overall) is that for any mainstream modellers also interested in causal structures the closure condition (and so adherence to deductivism) in practice constrains the sorts of structures that can reasonably be maintained. In effect they turn out always to be atomistic ${ }^{10}$ (whereas, I argue, as noted above, social structures are not typically atomistic at all but are mostly internally related and continuously in transformation, see Lawson 2003, chapter 2).

In total then, I fear I do not find Deichsel's criticisms of my ontological results and their methodological implications especially compelling. How about his critique of the way the results are achieved?

\footnotetext{
${ }^{10}$ Further where a power is explicitly acknowledged it must be treated (unrealistically) as always exercised. For example, if a form of rationality is imputed to agents, in order for an event regularity to be guaranteed, it is behaviour that must always be treated as rational.
} 
Here Deichsel seems to suppose that the only defence of the ontology I advance rests on 'common sense', and he then proceeds to dismiss this (his category, not mine) as notoriously vague.

This account of my defence of the ontological conception I maintain is so far from my position, that I can only infer that Deichsel missed important components of what I actually write. In my contributions I actually give various reasoned and lengthy defences of the nature of my ontological argumentation, and I can only refer Deichsel to certain instances (e.g., Lawson 1997, chapter 3; 2003, chapter 2; 2009b). But briefly, my methods employed for generating or defending the ontological results achieved include transcendental reasoning and immanent critique of contending positions. And indeed my assessment that social reality is structured, highly internally related, and so on, is defended both via transcendental analysis in terms of its relative explanatory power with respect to a range of phenomena (again see, e.g., Lawson 2003, chapter 2; or Lawson 1997, part 1; or even footnote 2 in page 53 above) as well as through imminent critique of contending ontological conceptions (see Lawson 2009b, for an overview). Until Deichsel provides a critique of such methods, there is little here for me to defend.

If Deichsel's critique of neither my ontological results nor the manner in which they are achieved is compelling, how about his critique of the whole ontological project in economics as a matter of principle? Deichsel opens the section headed “Against Lawson's pragmatic justification for realism" as follows:

Now let us see how Tony Lawson's critical realism scores against critical scrutiny. Where Mäki's work is rather neutral towards economic methodology, Lawson intends to overthrow economic orthodoxy. If one is inclined to accept the methodology of mainstream economics as it is and therefore does not share Lawson's view that the search for observable event regularities fundamentally contradicts the ontology that underlies social processes, there is little reason to follow his demand for more realism (Deichsel 2011, 34).

This assessment is surely (logically) correct, though language like "overthrow" is not mine. The point here though is that the nature of Deichsel's argumentation as a whole seems to suggest that Deichsel is doing more than stating the logic of the case; he himself is actually 
"inclined to accept the methodology of mainstream economics" with its emphasis on "event regularities".

In fact, looking at Deichsel's paper in broad perspective, an assessment that there is little wrong with modern mainstream practice seems to be what is driving Deichsel's opposition to my contributions. I have already noted that my arguments against the usefulness of methods of (theoretical) idealisation in economics are not so much contested as dismissed because of their (likely) destabilising implications for mainstream practice. But Deichsel seems similarly keen to be dismissive towards specific problematic or critical implications for the mainstream throughout his paper.

Thus in addition to the various assessments by Deichsel that are sketched or summarised above, we further find dotted evaluations and statements like the following: theories of rational agents are false but fruitfully so (p. 36); within modern mainstream economics there is "a plethora of well-confirmed conditioned predictions of tendencies and progress in their prediction [...] without the need to refrain from the underlying 'deductivist' structure” (p. 36); the picture that emerges from social ontology is "too messy" to support (presumably mainstream notions of) theorising (p. 36); [Lawson's] emphasis on empirical adequacy "excludes many forms of theorising that are commonly accepted to be useful or successful" (p. 38); and so on. But none of these assertions are backed up in any way; they only serve to persuade that the state of modern mainstream economics is just fine.

Parenthetically, support for the mainstream status quo seems equally evident in Deichsel's assessment of Uskali Mäki's position. Observing that "[in contrast with Lawson] Mäki is generally neutral or even affirmative concerning mainstream economic theory" (p. 27), Deichsel opens the section entitled "Against Mäki's pragmatic justification for realism" with the qualification: "Before criticising some of Mäki's arguments in support of realism, I should state that I accept many of his arguments and generally share his point of view-except for its realist branding" (p. 32).

So where does all this take us? If we put aside any semantic differences between Deichsel and myself, it is not clear that there is much necessary disagreement at the level of philosophy at all. Rather Deichsel seems to take essential issue with my assessment first of the (poor) state of health of modern mainstream economics, and then (and thus unsurprisingly) with the critical results of my ontological 
investigations including the methodological implications I draw for reorienting the discipline of modern economics.

As such, and bearing in mind the less than compelling case advanced against my ontological argumentation, I am inclined to conclude that it is my assessment that modern economics is far from being in a healthy state that is Deichsel's primary bone of contention. The topic on which we fundamentally disagree is the state of modern economics. This, however, is not something that is easily taken forward here and ultimately pinpoints a difference the reconciling of which has little to do with ontological realism anyway (the latter being something we both presuppose). But if the issues on which we actually differ are indeed ultimately matters of empirical assessment, not philosophical orientation, this at least points to the terms on which any further discussion can most usefully be taken forward.

\section{REFERENCES}

Deichsel, Simon. 2011. Against the pragmatic justification for realism in economic methodology. Erasmus Journal for Philosophy and Economics, 4 (1): 23-41. http://ejpe.org/pdf/4-1-art-2.pdf

Fullbrook, Edward (ed.). 2009. Ontology and economics: Tony Lawson and his critics. London and New York: Routledge.

Hausman, Daniel M. 1998. Problems with realism in economics. Economics and Philosophy, 14 (2): 185-213.

Hendry, David F. 1997. The role of econometrics in scientific economics. In Is economics becoming a hard science?, eds. Antoine d'Autume, and Jean Cartelier. Cheltenham: Edward Elgar, 172-196.

Lawson, Tony. 1997. Economics and reality. London and New York: Routledge.

Lawson, Tony. 2001. Two responses to the failings of modern economics: the instrumentalist and the realist. Review of Population and Social Policy, (10): 155-181.

Lawson, Tony. 2003. Reorienting economics. London and New York: Routledge.

Lawson, Tony. 2009a. Applied economics, contrast explanation and asymmetric information. Cambridge Journal of Economics, 33 (3): 405-420.

Lawson, Tony. 2009b. Underlabouring for substantive theorising (reply to Bjorn-Invar Davidsen). In Ontology and economics: Tony Lawson and his critics, ed. Edward Fullbrook. London and New York: Routledge, 58-82.

Lawson, Tony. 2009c. On the nature and roles of formalism in economics (reply to Geoffrey Hodgson). In Ontology and economics: Tony Lawson and his critics, ed. Edward Fullbrook. London and New York: Routledge, 189-231.

Lawson, Tony. 2009d. Provisionally grounded critical ontology (reply to Jack Vromen). In Ontology and economics: Tony Lawson and his critics, ed. Edward Fullbrook. London and New York: Routledge, 335-353. 
Lawson, Tony. 2009e. History, causal explanation, and "basic economic reasoning" (reply to Bruce Caldwell). In Ontology and economics: Tony Lawson and his critics, ed. Edward Fullbrook. London and New York: Routledge, 20-39.

Lucas, Robert E. 1986. Adaptive behaviour and economic theory. Journal of Business, 59 (4): 401-426.

Popper, Karl R. 1985 [1967]. The rationality principle. In Popper selections, ed. David Miller. Princeton (NJ): Princeton University Press, 357-365.

Tony Lawson is a reader in economics at the University of Cambridge (UK). He is organizer of the Cambridge Social Ontology Group and the Cambridge Realist Workshop. He has written extensively on issues in economic methodology, epistemology and explanation in social science, philosophical realism, and social ontology, particularly in his books Economics and reality (1997) and Reorienting economics (2003), and Ontology and economics: Tony Lawson and his critics (2008, edited by Edward Fullbrook).

Contact e-mail: <tony.lawson-at-econ.cam.ac.uk> 